\title{
Transient stress lymphocytosis uncovers the underlying B-cell lymphoproliferative disorder
}

\author{
Zhaodong Xu \\ Division of Hematopathology, Department of Pathology and Laboratory Medicine, the Ottawa Hospital, Ottawa, Ontario, \\ Canada
}

Correspondence: Zhaodong Xu. Address: Dept. of Pathology and Laboratory Medicine, Division of Hematopathology, The Ottawa Hospital, General Campus, 501 Smyth Road, Ottawa, Ontario, Canada, K1H 8L6. E-mail: zxu@toh.on.ca

Received: January 15, 2014

Accepted: March 4, 2014

Online Published: March 17, 2014

DOI : $10.5430 /$ crcp.v1n2p1

URL: http://dx.doi.org/10.5430/crcp.v1n2p1

\begin{abstract}
Transient stress lymphocytosis or stress induced lymphocytosis is a relative uncommon reactive process. It typically associates with emergency medical conditions, such as cardiac stress, sickle crises, abdominal pain, and trauma. Immunophenotypic analysis of stress induced lymphocytosis or transient stress lymphocytosis reveals an increase in absolute numbers of $\mathrm{T}, \mathrm{B}$, and natural killer cells with a normal immunophenotype. A clonal process has never been reported. Here we report a case of transient stress lymphocytosis revealing the underlying lymphoproliferative disorder.
\end{abstract}

\section{Key words}

B-cell, Lymphoproliferative disorder, Transient stress lymphocytosis, Immunophenotyping

\section{I ntroduction}

Lymphocytes are playing an important role in the immune system against pathogens and foreign proteins. Lymphocytosis, defined as an increased peripheral absolute lymphocytes count (ALC) $>4.0 \times 10^{9} / \mathrm{L}$, is caused by variable reasons in people older than 12 years old but is a physiological phenomena in neonates and young children. The causes of lymphocytosis in adult in general can be divided into two categories, reactive lymphocytosis (polyclonal) and clonal lymphocytosis (monoclonal) ${ }^{[1,2]}$.

In patients with reactive lymphocytosis, the lymphocyte count usually normalizes within < two months after resolution of underlying causes. The causes of reactive lymphocytosis can be further divided into infectious causes and non-infectious causes, with infectious causes account for majority, one of the common infectious causes of reactive lymphcytosis is infectious mononucleosis, caused by Epstein-Barr virus. Non-infectious causes of reactive lymphocytosis include hypersensitivity reactions ${ }^{[3]}$, Stress-induced lymphocytosis ${ }^{[4-6]}$, postsplenectomy lymphocytosis ${ }^{[7,8]}$ and persistent polyclonal B cell lymphocytosis ${ }^{[9]}$.

There are many causes of clonal lymphocytosis, which include acute or chronic lymphoproliferative disorders, such as monoclonal B cell lymphocytosis (MBL) ${ }^{[10,11]}$, chronic lymphocytic leukemia (CLL) ${ }^{[12]}$, acute lymphoblastic leukemia, and peripheralized follicular lymphoma or mantle cell lymphoma, etc ${ }^{[13]}$. Various modalities to demonstrate clonality besides the morphology are available, such as the presence of light chain restriction in B cell lymphoproliferative disorders 
by flow cytometry, an abnormal karyotype by cytogenetics, a clonal rearrangement of the immunoglobulin genes in different B cell lymphoma/leukemia and a clonal rearrangement of the $\mathrm{T}$ cell receptor in various $\mathrm{T}$ cell lymphoma/ leukemia by molecular tests. Patients with clonal lymphocytosis can manifest from asymptomatic to anemia, thrombocytopenia, leukocytosis, etc. Management of clonal lymphocytosis are depending on the underlying causes, may require from no treatment but with regular physicians visits to aggressive chemotherapy.

Mild clonal lymphocytosis can be easily missed without diligent morphological examination of peripheral blood films, especially in conditions with obvious underlying reactive causes. Here we report a case of transient stress lymphocytosis revealing the underlying lymphoproliferative disorder, which emphasize the importance of microscopic examination of peripheral blood films.

\section{Case presentation}

A 74-year-old man was admitted with acute kidney injury for possible hepatorenal syndrome with elevated creatinine of $428 \mu \mathrm{mol} / \mathrm{L}$. Patient had multiple medical modalities including hepatic encephalopathy, ethanol cirrhosis, pulmonary hypertension, congestive heart failure, an unknown cause of chronic normocytic anemia (mean Hgb level of $84 \mathrm{~g} / \mathrm{L}$ ) and thrombocytopenia (mean platelet count of $70 \times 10^{9} / \mathrm{L}$ ), of which, a bone marrow examination was planned, but was never performed. Physical examination demonstrated hepatosplenomegaly without lymphadenopathy. He was treated in the medical ward with multidisciplinary care.

Two months after admission, patient suffered a massive spontaneous intraperitoneal bleeding (estimated blood loss of 3 L - 4 L). Computed tomography (CT) of abdomen showed enlarged spleen and a significant large volume of hemoperitoneum. A sentineal clot around the posterior liver and spleen implicated these sites as potential sources for bleeding. A blood count showed sudden drop of hemoglobin, from $89 \mathrm{~g} / \mathrm{L}$ to $62 \mathrm{~g} / \mathrm{L}$; neutrophilia, from $2.0 \times 10^{9} / \mathrm{L}$ to $8.7 \times 10^{9} / \mathrm{L}$; lymphocytosis, from $2.6 \times 10^{9} / \mathrm{L}$ to $10.2 \times 10^{9} / \mathrm{L}$; and mild increase of platelets, $84 \times 10^{9} / \mathrm{L}$ to $118 \times 10^{9} / \mathrm{L}$. The pattern of blood count changes was consistent with acute bleeding concurrent with stress induced lymphocytosis or transient stress lymphocytosis. A regular blood film demonstrated mild neutrophilia and lymphocytosis with small size of abnormal lymphocytes with nuclear indentation and background smudge cells, some of the lymphocytes had cleaved nuclei, suspicious of lymphoproliferative disorder (see Figure 1). Thus, a flow cytometry was performed on the peripheral blood to investigate the "transient stress lymphocytosis".

Figure 1. Lymphocytosis with small lymphocytes with nuclei indentation. An abnormal lymphocyte with cleaved nuclei is shown in inlet

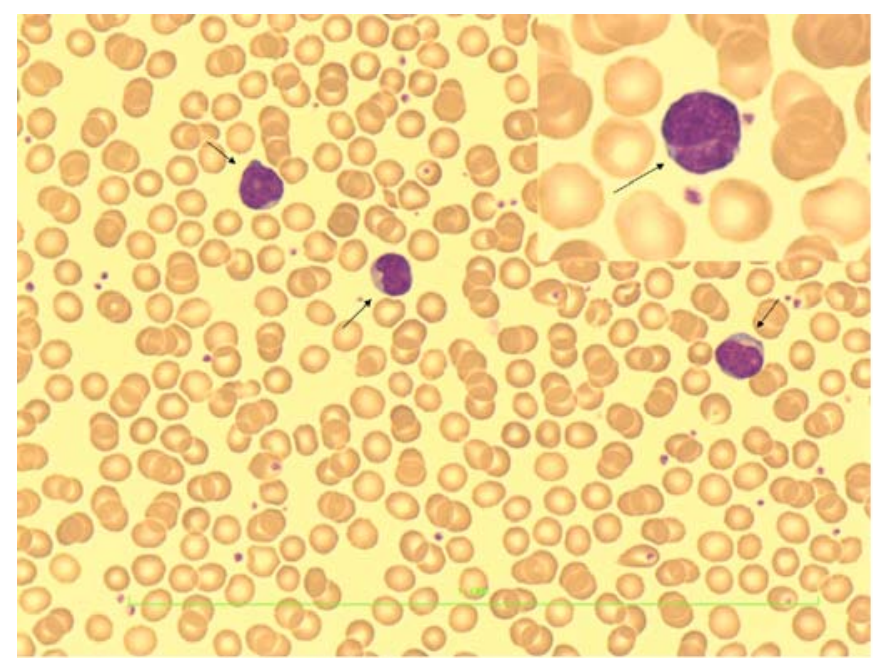

Flow immunophenotyping identified a lymphocytes population, majority of which were B cells that were positive for CD19+, CD5+, CD20+ (strong), HLA-DR+, CD22+, FMC-7+, CD25+, and CD38+, but were negative for CD10-, CD23-, and CD103-. These abnormal B cells showed a kappa light chain restriction, demonstrating a clonal process (see Figure 2). 
The immunophenotyping was consistent with B cell lymphoproliferative disorder, combined with peripheral abnormal lymphocytes morphology with cleaved nuclei; mantle cell lymphoma was suspected but not confirmed ${ }^{[14]}$. Other differential diagnosis in this case may include MBL with a non-CLL phenotype, etc. Next day, the lymphocytes normalized almost back to the normal range from $10.2 \times 10^{9} / \mathrm{L}$ to $4.7 \times 10^{9} / \mathrm{L}$ with persistent neutrophilia. Unfortunately two days later, patient died of Asystole. Cytogenetics and FISH study was not performed as patient was demise and patient's family declined the request, thus a firmed diagnosis of mantle cell lymphoma could not be reached.

Figure 2. Flow cytometry of peripheral blood shows increased abnormal B cells population with Kappa light chain restriction, consistent with a clonal process
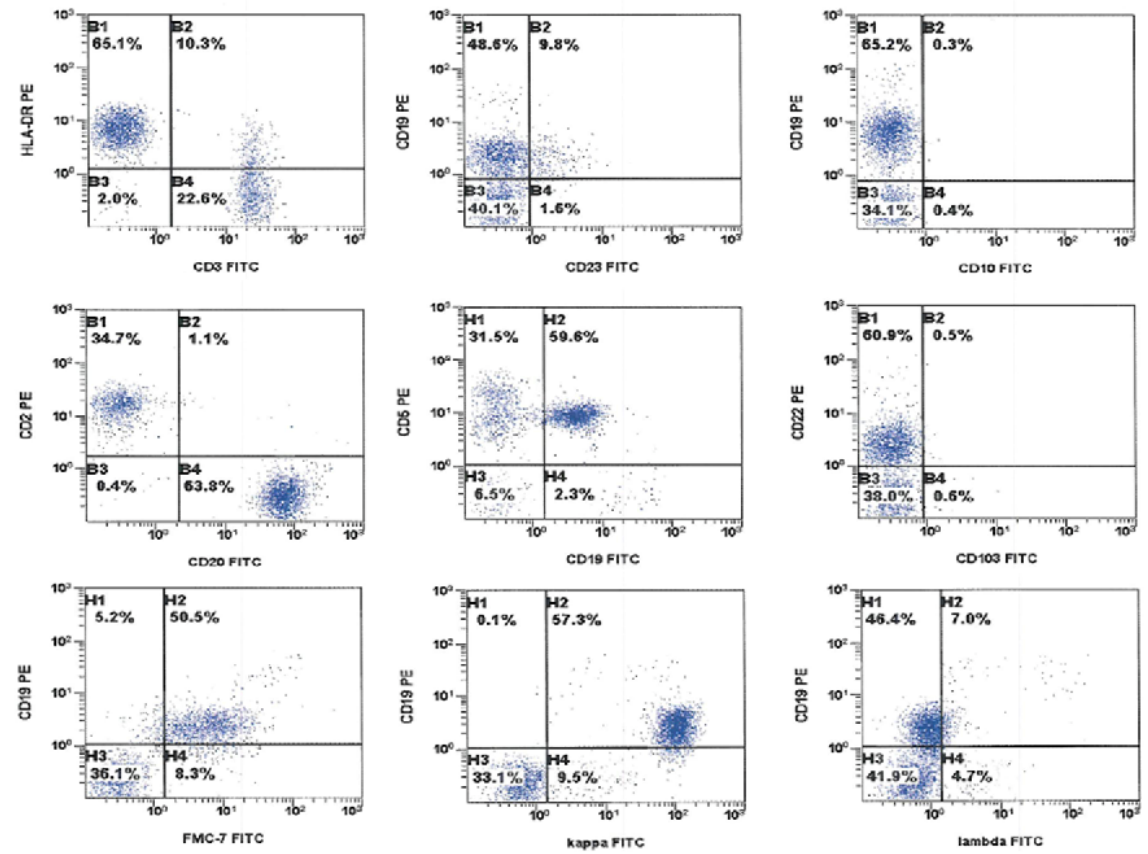

\section{Discussion}

Lymphocytosis in elderly people is common clinical encounter in daily practice. One of the intriguing clinical questions is whether the lymphocytosis is reactive or clonal. The best predictors of clonal lymphocytosis are the age and ALC, with approximately $60 \%$ of individuals over 50 years old and ALC $>4.0 \times 10^{9} / \mathrm{L}$ having clonal lymphocytosis detected by flow cytometry ${ }^{[1]}$. The first clue for clonal lymphocytosis is usually derived from the careful peripheral blood films examination. Certain clonal lymphocytosis can reveal specific features with their morphology. For example, Lymphocytes in CLL are usually small mature appearing with clump chromatin and some of the lymphocytes are easily broken when preparing the slides, these broken lymphocytes are so called "smudge cells". Lymphocytes in follicular lymphoma and mantle cell lymphoma can be small with cleaved nuclei. But sometimes it is difficult to differentiate between the reactive and clonal lymphocytosis by morphology alone, especially in conditions with known underlying reactive causes superimposed with clonal process, thus further investigation with other modalities is required, such as flow cytometry, molecular tests, etc.

Stress induced lymphocytosis or transient stress lymphocytosis is a relative uncommon cause of reactive lymphocytosis in general population, but it is quite common in medical emergencies, especially cardiac emergencies, sickle disease with crisis, and life threatening bleeding as demonstrated in this case. The lymphocytosis generally ranges from 4.0 to $10.4 \times$ 109/L with an increase in the total WBC, absolute lymphocytes, absolute neutrophils, and platelet counts. It usually resolves within 24 hours to 48 hours after its diagnosis without specific treatment for the lymphocytosis. A normal immunophenotype is observed with an increase in absolute counts of T, B, and NK cells with the flow immunophenotypic analysis in patients with stress induced lymphocytosis or transient stress lymphocytosis ${ }^{[14,15]}$. A clonal process has never been documented in the medical literatures. 
Our case is rare and interesting in that due to the normal blood count, the underlying B-cell lymphoproliferative disorder was never suspected, even though the patient has a chronic normocytic anemia and thrombocytopenia in the past. Only due to the stress induced lymphocytosis and abnormal morphology of the lymphocytes, is the underlying B-cell lymphoproliferative disorder uncovered. The case emphasizes the importance of morphological examination of peripheral blood films and clinical vigilance regarding the rare cases with clonal lymphocytosis superimposed with underlying clinical reactive conditions.

\section{Conflict of interests}

The author declares that he has no conflict of interests.

\section{Author contribution and acknowledgement}

$\mathrm{Dr}$. Zhaodong $\mathrm{Xu}$ is responsible for the pathological diagnosis of the case and wrote the manuscript.

Ms. Rebecca Xu (Undergraduate Faculty of Science, University of Ottawa, Ottawa, ON, K1N 6N5, Canada) is responsible for the editing of the manuscript.

\section{References}

[1] Andrews JM, Cruser DL, Myers JB, Fernelius CA, Holm MT, Waldner DL. Using peripheral smear review, age and absolute lymphocyte count as predictors of abnormal peripheral blood lymphocytoses diagnosed by flow cytometry. Leuk Lymphoma. 2008; 49: 1731-1737. PMid: 18798107. http://dx.doi.org/10.1080/10428190802251787

[2] Carney D. Peripheral blood lymphocytosis--what is the threshold for further investigation? Leuk Lymphoma. 2008; 49: 1659-1661. PMid: 18798099. http://dx.doi.org/10.1080/10428190802389843

[3] Kano Y, Shiohara T. The variable clinical picture of drug-induced hypersensitivity syndrome/drug rash with eosinophilia and systemic symptoms in relation to the eliciting drug. Immunol Allergy Clin North Am. 2009; 29: 481-501. PMid: 19563993. http://dx.doi.org/10.1016/j.iac.2009.04.007

[4] Teggatz JR, Parkin J, Peterson L. Transient atypical lymphocytosis in patients with emergency medical conditions. Arch Pathol Lab Med. 1987; 111: 712-714. PMid: 3632284.

[5] Pinkerton PH, McLellan BA, Quantz MC, Robinson JB. Acute lymphocytosis after trauma--early recognition of the high-risk patient? J Trauma. 1989; 29: 749-751. PMid: 2738972. http://dx.doi.org/10.1097/00005373-198906000-00009

[6] Groom DA, Kunkel LA, Brynes RK, Parker JW, Johnson CS, Endres D. Transient stress lymphocytosis during crisis of sickle cell anemia and emergency trauma and medical conditions. An immunophenotyping study. Arch Pathol Lab Med. 1990; 114(6): 570-576. PMid: 2095748.

[7] Juneja S, Januszewicz E, Wolf M, Cooper I. Post-splenectomy lymphocytosis. Clin Lab Haematol. 1995; 17: 335-337. PMid: 8697729.

[8] Garcia-Suarez J, Prieto A, Reyes E, Arribalzaga K, Perez-Machado MA, Lopez-Rubio M, et al. Persistent lymphocytosis of natural killer cells in autoimmune thrombocytopenic purpura (ATP) patients after splenectomy. Br J Haematol. 1995; 89: 653-655. PMid: 7734372. http://dx.doi.org/10.1111/j.1365-2141.1995.tb08382.x

[9] Lesesve JF, Troussard X. Persistent polyclonal B-cell lymphocytosis. Blood. 2011; 118: 6485. PMid: 22279623. http://dx.doi.org/10.1182/blood-2011-01-331082

[10] Matos DM, Falcao RP. Monoclonal B-cell lymphocytosis: a brief review for general clinicians. Sao Paulo Med J. 2011; 129: 171-175. PMid: 21755252.

[11] Mowery YM, Lanasa MC. Clinical aspects of monoclonal B-cell lymphocytosis. Cancer Control. 2012; 19: 8-17.

[12] Swerdlow SH, Campo E, Harris NL, Jaffe ES, Pileri SA, Stein H, et al. WHO classification of tumors of haematopoietic and lymphoid tissues. France: International Agency for Research on Cancer. 2008.

[13] Ferrer A, Salaverria I, Bosch F, Villamor N, Rozman M, Beà S, et al. Leukemic involvement is a common feature in mantle cell lymphoma. Cancer. 2007; 109: 2473-2480. PMid: 17477385. http://dx.doi.org/10.1002/cncr.22715

[14] Mills PJ, Berry CC, Dimsdale JE, Ziegler MG, Nelesen RA, Kennedy BP. Lymphocyte subset redistribution in response to acute experimental stress: effects of gender, ethnicity, hypertension, and the sympathetic nervous system. Brain Behav Immun. 1995; 9: 61-69. PMid: 7620211. http://dx.doi.org/10.1006/brbi.1995.1006

[15] Karandikar NJ, Hotchkiss EC, Mckenna RW, Kroft SH. Transient stress lymphocytosis: an immunophenotypic characterization of the most common cause of newly identified adult lymphocytosis in a tertiary hospital. Am J Clin Pathol. 2002; 117(5): 819-825. PMid: 12090434. http://dx.doi.org/10.1309/DU0B-EBFL-3EXY-VUFP 